\begin{tabular}{l}
\hline Alimentary Pharmacology \\
\hline \& Therapeutics \\
\hline
\end{tabular}

\title{
The changing face of hospitalization due to gastrointestinal bleeding and perforation
}

\begin{tabular}{|c|c|}
\hline Journal: & Alimentary Pharmacology \& Therapeutics \\
\hline Manuscript ID: & APT-0637-2010.R2 \\
\hline Wiley - Manuscript type: & Original Scientific Paper \\
\hline $\begin{array}{r}\text { Date Submitted by the } \\
\text { Author: }\end{array}$ & $11-\mathrm{Dec}-2010$ \\
\hline Complete List of Authors: & $\begin{array}{l}\text { Lanas, Angel; University Hospital Lozano Blesa, Gastroenterology; } \\
\text { University of Zaragoza. School of Medicine, Medicine; CIBERehd } \\
\text { Garcia Rodriguez, Luis Alberto; Centro Español de Investigacion } \\
\text { Farmacoepidemiologica (CEIFE) } \\
\text { Polo-Tomas, Monica; CIBERehd, Division of Gastroenterology } \\
\text { Ponce, Marta; Hospital la Fe, Gastroenterology Unit } \\
\text { Quintero, Enrique; Hospital Universitario de la Laguna, } \\
\text { Gastroenterology } \\
\text { Perez-Aisa, Maria; Hospital Costa del Sol, Gastroeneterology } \\
\text { Gisbert, Javier; Hospital de la Princesa-CIBERehd, Division of } \\
\text { Gastroenterology } \\
\text { Bujanda, Luis; Hospital Donostia. CIBERehd, Gastroenterology } \\
\text { Castro, Manuel; Hospital de Valme. CIBERehd, Gastroenterology } \\
\text { Department } \\
\text { Muñoz, Maria; University Hospital Lozano Blesa, Gastroenterology } \\
\text { Del Pino, Maria Dolores; University Hospital Lozano Blesa, } \\
\text { Gastroenterology } \\
\text { Garcia, Santiago; Hospital Universitario Miguel Servet, } \\
\text { Gastroenterology } \\
\text { Calvet, Xavier; Parc Tauli, Gastroenterology }\end{array}$ \\
\hline Keywords: & $\begin{array}{l}\text { Peptic ulcer disease }<\text { Disease-based, Diverticular disease }< \\
\text { Disease-based, Stomach and duodenum }<\text { Organ-based, } \\
\text { Epidemiology }<\text { Topics, NSAIDs }<\text { Topics }\end{array}$ \\
\hline
\end{tabular}

\section{SCHOLARONE \\ Manuscripts}




\section{The changing face of hospitalization due to gastrointestinal bleeding and perforation}

\section{Authors:}

Angel Lanas, ${ }^{1,2,3}$ Luis A. García-Rodríguez, ${ }^{4}$ Mónica Polo-Tomás ${ }^{2}$, Marta Ponce $^{5,2}$, Enrique Quintero, ${ }^{6}$ Maria Angeles Perez-Aisa ${ }^{7}$, Javier P. Gisbert ${ }^{8,2}$ Luis Bujanda $^{9,2}$, Manuel Castro ${ }^{10,2}$, Maria Muñoz ${ }^{1}$, Dolores Del-Pino ${ }^{12}$, Santiago Garcia $^{13}$, Xavier Calvet ${ }^{14,2}$

\section{Affiliations}

${ }^{1}$ Servicio de Aparato Digestivo, Hospital Clínico. Universidad de Zaragoza. Spain

${ }^{2}$ Centro de Investigación Biomédica en Red de enfermedades hepáticas y digestivas (CIBERehd). Spain

${ }^{3}$ Instituto Aragonés de Ciencias de la Salud (IACS)

${ }^{4}$ Centro Español de Investigación Farmacoepidemiológica. Madrid. Spain

${ }^{5}$ Servicio de Aparato Digestivo. Hospital La Fe. Valencia

${ }^{6}$ Servicio de Aparato Digestivo. Hospital Universitario de Canarias. La Laguna. Tenerife. Spain.

7. Servicio de Aparato Digestivo. Hospital Costa del Sol. Marbella. Spain.

${ }^{8}$. Servicio de Aparato Digestivo. Hospital de la Princesa. Madrid. Spain.

${ }^{9}$ Servicio de Aparato Digestivo. Hospital Donostia Universidad del País Vasco. San Sebastián. Spain.

${ }^{10}$ Servicio de Aparato Digestivo. Hospital de Valme.- Sevilla. Spain.

${ }^{11}$. Servicio de Aparato Digestivo. Hospital de Asturias. Oviedo. Spain.

12. Servicio de Codificación. Hospital Clínico Universitario. Zaragoza. Spain

${ }^{13}$ Servicio de Aparato Digestivo. Hospital Universitario Miguel Servet. Zaragoza. Spain

${ }^{14}$ Servicio de Aparato Digestivo. Hospital de Sabadell. Barcelona. Spain

\section{Short title: Trends in GI hospitalizations}

\section{To whom correspondence should be addressed:}

Angel Lanas. Servicio de Aparato Digestivo. Hospital Clínico Universitario. C/ San Juan Bosco 15. 50009 Zaragoza. Spain. Phone: 34 976765786; Fax: 34 976765787). Email: alanas@unizar.es 


\begin{abstract}
:
Background: Temporal changes in the incidence of cause-specific gastrointestinal (Gl) complications may be one of the factors underlying changing medical practice patterns. Aim: To report temporal changes in the incidence of five major causes of specific gastrointestinal (GI) complication events. Methodology: Population-based study of patients hospitalized due to GI bleeding and perforation from 1996-2005 in Spain. We report crude rates, and estimate regression coefficients of temporal trends, severity, and recorded drug use for 5 frequent Gl events. Gl hospitalization charts were validated by independent review of large random samples. Results: The incidence per 100,000 person-years of hospitalizations due to upper Gl ulcer bleeding and perforation decreased over time (from 54.6 and 3.9 in $1996\left[R^{2}=0.944\right]$ to 25.8 and 2.9 in 2005 [ $\left.R^{2}=0.410\right]$, respectively). On the contrary, the incidence per 100,000 person-years of colonic diverticular and angiodysplasia bleeding increased over time (3.3 and 0.9 in $1996\left[R^{2}=0.443\right]$ and 8.0 and 2.6 in 2005 $\left[\mathrm{R}^{2}=0.715\right]$, respectively). A small increasing trend was observed for the incidence per 100,000 person-years of intestinal perforations (from 1.5 to 2.3 events). Based on data extracted from the validation process, recent recorded drug intake showed an increased frequency of anticoagulants with colonic diverticular and angiodysplasia bleeding, whereas NSAID and low-dose aspirin use were more prevalent in peptic ulcer bleeding and colonic diverticular bleeding respectively. Conclusions: From 1996-2005, hospitalizations due to peptic ulcer bleeding and perforation have decreased significantly, whereas the number of cases of colonic diverticular and angiodysplasia bleeding have increased.
\end{abstract}

Key words: peptic ulcer, bleeding, perforation, angiodysplasia, diverticulum 


\section{Background}

Gastrointestinal (Gl) complications are major causes of hospitalization. Major therapeutic advances in the treatment and prevention of peptic ulcer diseases have been implemented in the past decade, which should contribute to a significant decrease in the incidence and mortality due to peptic ulcer diseases. Opposing trends in peptic ulcer complications such as bleeding or perforation have been reported in different countries, and no decrease or increase in hospitalizations due to peptic ulcer bleeding complications have been observed (1-6). More recently, two studies from different geographical areas suggested that there has been a marked decrease in the incidence of upper Gl complications and a slight increase in the incidence of lower Gl complications $(7,8)$; however, the specific lesions leading to these changes have not been analyzed. Furthermore, the time trends for bleeding and perforation may not be parallel, since the underlying pathogenic mechanisms and risk factors could diverge $(9,10)$. Additionally, the exact source of lower GI complications are often more difficult to identify than upper Gl complications because of the anatomic complexity of the lower gut and available diagnostic tests. Among the causes of lower GI bleeding, colonic diverticuli and angiodysplasia are two lesions which could explain, at least in part, the recent trends, since age was found to be one of the main risk factors for hospitalizations (7). However, the time trends and clinical characteristics of hospitalizations owing to these two lesions have not been reported.

Prevention strategies and optimization of hospital resources require a clear understanding of the type of pathology causing hospitalization. In a previous report, we presented the overall time trends of hospitalizations due to Gl complications, (7) which were obtained from a data-base including information provided by 10 Spanish general hospitals representative of the entire country (11). Now, as part of the pre-specified analysis plan, we aim to characterize and analyze in detail the time trends for hospitalizations due to five specific major causes of Gl complications; namely, peptic ulcer bleeding, peptic ulcer perforation, intestinal perforation, colonic diverticular bleeding, and bleeding caused by angiodysplasia. We believe that these data are needed since, as discussed above, the available literature for some of these causes and 
the comparative trends among them are sparse or absent. Additionally, we also describe the severity characteristics and recorded drug use for each of these entities.

\section{Methods:}

\section{Setting and data collection}

The study (7) was approved by the Institutional Review Board of Aragón and was carried out in 10 Spanish general hospitals distributed across the entire country, serving a population of $3,281,973$ people in 1996 and $3,681,822$ in 2005. Based on previous reports (11), the population covered by these hospitals was representative of the whole country, where the majority $(80 \%)$ of the population uses the Spanish NHS, which provides open access free-to-all healthcare services including hospitals, drugs, and diagnostic and therapeutic procedures.

The methodology of data collection was described in our first report of this study (7). Each hospital provided data from January 1, 1996 to December 31, 2005 on patients identified with a primary discharge diagnosis, coded according to the International Classification of Diseases $\left(9^{\text {th }}\right.$ revision, Clinical Modification [ICD9]), for the 5 specific diagnoses investigated in this study (1). The codes used were as follows: (1) upper Gl Bleeding, gastric ulcer with bleeding, 531.00, 531.01, 531.20, 531.21, 531.40, 531.41, 531.60, and 531.61; duodenal ulcer with bleeding, 532.00, 532.01, 532.20, 532.21, 532.40, 532.41, 532.60, and 532.61; peptic ulcer with bleeding, 533.00, 533.01, 533.21, 533.40, 533.41, 533.60, and 533.61; gastrojejunal ulcer with bleeding, 534.00, 534.01, $534.20,534.21,534.40,534.41,534.60$, and 534.61; gastric ulcer with perforation, 531.10, 531.11, 531.20, 531.21, 531.50, 531.51, 531.60, and 531.61. For (2) upper GI perforation, duodenal ulcer with perforation, codes $532.10,532.11,532.20,532.21,532.50,532.51,532.60$, and 532.61; peptic ulcer with perforation, 533.10, 533.11, 533.21, 533.50, 533.51, 533.60, and 533.61; gastrojejunal ulcer with perforation, 534.10, 534.11, 534.20, 534.21, $534.50,534.51,534.60$, and 534.61; and for (3) Gl perforation, intestinal perforation, 569.83; and for (4) diverticuli, diverticulosis with bleeding, 562.02 
and 562.12; diverticulitis with bleeding, 562.03 and 562.13; and finally, for (5) angiodysplasia, 569.85 .

The primary discharge diagnosis was considered to be the cause leading to hospitalization based on the clinical judgment of the physician who managed the patient. In this way, each hospitalization event is unequivocally classified according to the main diagnosis together with other variables (7). We only included bleeding or perforation events that occurred in the community and excluded those that developed after hospitalization, since they probably represent a group different from our target population. The type and number of variables provided by each hospital were the same and were introduced in a common database specifically designed for this study.

\section{Validation process}

In brief and as described previously (7), we validated around $10 \%$ of events with specific codes. However, since there was no experience or previous report on the accuracy of some undefined events from the lower Gl tract codes, we undertook a more extensive validation process for intestinal perforation to study the exact location of the perforation event (e.g. small vs. large bowel). The selection of episodes available in each centre was carried out using the "SAMPLE" procedure available in the SPSS program (SPSS, Chicago, IL USA). This information was introduced into a second database along with other variables which included the original diagnosis code (ICD9) undergoing validation and the final diagnosis after the validation process. Data were coded anonymously. The process of validating the codes and chart review was carried out by gastroenterologists or trained GI residents with experience in these types of studies $(7,11)$. These investigators ensure the appropriate interpretation of data and tests carried out during the hospitalization event. In addition to validation of the diagnostic codes, this process allowed us to collect additional information including death outcome, number of days of hospitalizations, number of comorbidities, lowest $\mathrm{Hb}$ level detected, number of units of blood transfusions, and recorded drug use. The severity and burden of the events for this report were based on the following variables: (a) death rate, (b) days of 
hospitalization, (c) number of diagnostic procedures, (d) weight of diagnosisrelated groups (DRG), (e) number of comorbidities, (f) lowest $\mathrm{Hb}$ level recorded during hospitalization, and (g) number of blood units transfused as described elsewhere (12).

We considered only recent use of drugs when they were taken by patients within 7 days before the date of hospitalization. The data entry was carried out by staff trained and experienced in managing databases, which was designed to minimize the data entry errors. One in five questionnaires was completely checked, and virtually no data entry errors were found.

\section{Management and analysis of data}

The data obtained from each hospital was entered in the two databases; one included the information gathered from the Minimum Basic Data Set (MBDS) and the other contained the information collected during the validation process. Time trends were reported based on the first database (MBDS), whereas data reported for severity of events and drug use was based on the database obtained from the validation and chart review process. A data analysis plan was pre-determined in advance for each database. Estimates of the actual frequencies were based on the validation process. Outcome variables are reported as rates, mean (SD), and 95\% confidence interval (CI) depending on the type of variable. Rates were calculated overall, by year, and by source of the event. We estimated both crude and age- and sex-adjusted incidence rates with $95 \% \mathrm{Cl}$ for the five Gl events. However, since the number of events was not large enough in 4 of the 5 codes to provide accurate age- and sex-adjusted rates, we report only crude rates. Wherever it may apply, data from different years (mean $\pm S D$ ) were analyzed by one-way analysis of variance followed by unpaired Student's t-test. Additionally, we estimated regression coefficients of the incidence trend line from 1996 to 2005 with the ordinary least squares method. Categorical data were analyzed by Chi-square, and logistic regression analysis was performed to estimate the effect of a number of risk factors comparing upper versus lower Gl events. Because of the multiple comparisons made for some of the analyses, values were considered statistically significant 
when $p$-values were $<0.01$. All statistics were carried out with Excel (Microsoft Office 2000), SPSS (Chicago, IL USA), and STATA (StataCorp, 2005, TX USA).

\section{Results}

\section{Time trends of events}

Data obtained from the database collecting the MBDS information provided by the participant hospitals showed a statistically significant decrease in the incidence rate of peptic ulcer bleeding as well as ulcer perforation from 1996 to 2005 (Figures 1 and 2). These decreasing trends were seen for both gastric and duodenal ulcer bleeding and perforations (data not shown). On the contrary, the trends for both colonic diverticular and bleeding due to colonic angiodysplasia showed a statistically significant increase over the same time period (Figures 1 and 2). Intestinal (lower Gl) perforations showed a nonsignificant increase over the same time period. Validation of codes showed > $90 \%$ accuracy for the $5 \mathrm{Gl}$ complications (Table 1). Incidence rates were adjusted according to the confirmation obtained with the manual chart review.

Based on the validation process of the 5 diagnostic codes identified in 2082 cases, $53.7 \%$ of intestinal perforations were located in the large bowel and $39 \%$ in the small bowel, whereas the remaining $7.2 \%$ were ascribed to the lower Gl tract without further site specification. Validation of codes for peptic ulcer perforation showed that $6.5 \%$ of cases were indeed intestinal perforations. Among cases coded as diverticular bleeding, the validation process showed that $1 \%$ of cases were actually upper Gl bleeding events, and another $1 \%$ were unconfirmed events. Among those with angiodysplasia, 2.9\% were upper GI bleeding events and in $1.4 \%$ of cases the source could not be ascribed to any cause. Finally, among peptic ulcer bleeds, only $1.5 \%$ were lower Gl bleeding events and in $0.3 \%$ of cases the source could not be identified.

The age and gender distribution was markedly different across the 5 causes of hospitalization (Table 2). Patients with bleeding from the colonic diverticuli or angiodysplasia were older than those with other causes for hospitalization, whereas males were predominant among those with peptic ulcer perforation and bleeding. Very similar results were found in the validation random sample (data not shown). 
Overall, the case fatality rates were higher for perforation than for bleeding events (intestinal perforation > peptic ulcer perforation > bleeding angiodysplasia > peptic ulcer bleeding > diverticular bleeding). Overall mortality trends did not change over time during the period studied for intestinal or peptic ulcer perforation or angiodysplasia or diverticular bleeding (specific information concerning these mortality trends can be seen on-line in "Supporting Information Table 1").

\section{Severity of events and drug use}

The review of charts provided an opportunity to collect a number of variables that described the severity of the different types of events. The case fatality rate was similar to that reported above in the overall sample. The length of hospitalization was longer in patients with perforation than for those with bleeding events, and the weight of DRG (an indirect measure of hospitalization costs for each type of event) was higher for complications in the lower GI tract when compared with those from the upper Gl tract. The number of comorbidities was greater in patients with colonic diverticular bleeding and angiodysplasia bleeding compared with the other type of lesions studied. As expected, hemoglobin decline and the number of blood units transfused were higher in patients with bleeding events than in those with perforations (specific information concerning the severity of events based on chart validation can be seen on-line in "Supporting Information Table 2").

Detailed recorded drug use concerning nonsteroidal anti-inflammatory drugs (NSAIDs), proton pump inhibitors (PPI), and anti-platelet agents can be seen on-line in "Supporting Information Table 3". Peptic ulcer and diverticular colonic bleeding had the highest NSAID/aspirin drug use compared with cases of perforation and even bleeding from GI angiodysplasia. PPI use was more frequently recorded in patients with colonic and angiodysplasia bleeding events. Recorded anticoagulant use was high in patients with diverticular bleeding and in patients with angiodysplasia. 


\section{Discussion}

This study shows that hospitalizations due to both peptic ulcer bleeding and perforations progressively and importantly decreased from 1996 to 2005. These trends were not observed for other types of bleeding or perforation events from the lower GI tract. In fact, we found that the incidences of colonic diverticular bleeding or angiodysplasia are increasing, whereas the rate of intestinal perforation remains virtually stable with a slight increase over the study period.

There is wide agreement that hospitalizations due to uncomplicated peptic ulcer are decreasing over time $(1,2)$, but there were discrepancies between hospitalizations on rates due to complicated peptic ulcers. Our results agree with data from Sweden $(14,15)$ and the USA (8) showing that hospitalizations due to peptic ulcer bleeding are decreasing. However, these data are not in agreement with reports from other European countries $(3,4,5$, $6,16)$, which show either no decrease or even an increase in hospitalizations for this type of event. The reasons for these discrepancies are unclear, since a decrease of $H$. pylori infection among the population, increasing $H$. pylori eradication therapy, and increasing PPI use across Europe should be accompanied by a progressive decrease in peptic ulcer complications $(14,15$, 17). The variability in the use of low-dose aspirin (ASA) and gastro-protective treatments between countries may partly explain these differences $(18,19)$, but our study and those reporting decreasing peptic ulcer bleeding rates collected data from more recent years and were population-based $(7,8)$.

Our data also show very low rates of mortality due to peptic ulcer bleeding, which is consistent with other studies $(8,14,15)$. The lack of improvement in case fatality rates is usually linked to a progressively aging population with increasing numbers of co-morbidities, despite data that show better bleeding management strategies associated with reduction in the risk of rebleeding and a reduced need for surgery (20). In any case, our data agree with a recent USA report (8) that shows an overall decrease (absolute numbers) 
in in-hospital deaths linked to Gl bleeding diagnoses between 1998 and 2006, owing to a decrease in the number of hospitalizations.

Time trends on peptic ulcer perforation are rarely reported and those available show no change or small changes overtime $(9,10,21)$. Here we report a clearly decreasing trend $(\sim 50 \%)$ in peptic ulcer perforation from 1996 to 2005 , which is consistent with a decrease in the overall incidence of peptic ulcer and peptic ulcer complications. The decrease in incidence of hospitalizations owing to peptic ulcer perforation was not associated with a decrease in case fatality rates over this time.

Other studies have reported time trends for peptic ulcer bleeding or perforation, but not other sources of Gl bleeding or perforation. In our first overall report of this study (7), we pointed out that the ratio of hospitalizations for upper vs. lower GI complications has changed from a 4:1 to $1.4: 1$. Here we report that two common reasons for hospitalizations, colonic diverticular and angiodysplasia bleeding, are more frequent today than 10 years ago. A progressively aging population and the increasing use of NSAIDs and low-dose ASA may explain, at least in part, these results. (22). PPI use was more frequently recorded in patients hospitalized with diverticular bleeding and bleeding due to angiodysplasia than in those with peptic ulcer bleeding. This could support the concept that PPI use is associated with the prevention of upper GI but not lower Gl complications, but age and its accompanying greater number of co-morbidities could also explain the observed higher prevalence of PPI use. Eventually, it must be noted that anticoagulant use, a growing clinical practice, is especially associated with bleeding events and overall with diverticular and angiodysplasia bleeding.

Trends on intestinal perforation are rarely reported. Here we report overall intestinal (small and large bowel) perforation rates and found that these rates remained stable over time, although with a numerical tendency to increase in agreement with the data reported from the UK on diverticular perforation (23). 
Our study has strengths and limitations. A strength is that we carried out an extensive validation of events. This is especially important for intestinal perforation, and diverticular and bleeding from angiodysplasia lesions. Contrary to peptic ulcer bleeding and perforation, these have rarely been reported in the literature. Therefore, these ICD-9 codes have rarely been validated in observational studies. This is of major importance since the diagnostic process of diseases from the lower $\mathrm{Gl}$ tract is more complex than those used in the upper GI tract.

The study also has limitations. First, undefined codes such as "Gl bleeding" may include patients with both peptic ulcer bleeding and bleeding from diverticular disease and angiodysplasia lesions. This means that the reported incidence and trends reflect minimum rates, since it is possible that a proportion of patients with the events studied here may not be counted because of misclassification under undefined codes. In our previous report, we observed that this proportion was constant over time (7). Another limitation refers to data on drug use, which relies on data recorded in charts and are subject to reporting bias in the clinical history. Ascertainment of NSAID, ASA, and PPI use may be more frequently searched in patients with peptic ulcer complications than in diverticular or angiodysplasia bleeding events. Finally, our mortality rates refer to in-hospital mortality, as we could not provide 30-day mortality, since most patients were discharged from hospital before this window of time.

In summary, our study shows that, over the past decade, there has been a significant decrease in hospitalization rates for peptic ulcer bleeding and perforation, but an increase for colonic diverticular and angiodysplasia bleeding, with virtually no change in intestinal perforation. These data show a clear change in the incidence of hospitalizations due to Gl complications over time, with upper Gl events decreasing and lower Gl events increasing. Since the severity of these events are very different, these data should be of interest for improving clinical practice in terms of preventive strategies and to better address the increasing prevalence of lower Gl events, specifically the increase in colonic diverticular and angiodysplasia bleeding. 


\section{References:}

1. Sung JJ, Kuipers EJ, El-serag HB, Systematic review. The global incidence and prevalence of peptic ulcer disease. Aliment Pharmacol Ther 2009; 29: 938-46.

2. Sonnenberg A. Time trends of ulcer mortality in Europe. Gastroenterology. 2007 Jun;132(7):2320-7. Epub 2007 Apr 14.

3. Post PN, Kuipers EJ, Meijer GA. Declining incidence of peptic ulcer but not of its complications: a nation-wide study in The Netherland. Aliment Pharmacol Ther. 2006 Jun 1;23(11):1587-93.

4. Ohmann C, Imhof M, Ruppert C, et al. Time-trends in the epidemiology of peptic ulcer bleeding. Scand J Gastroenterol 2005; 40: 914-20.

5. Kang JY, Elders A, Majeed A, Maxwell JD, Bardhan KD. Recent trends in hospital admissions and mortality rates for peptic ulcer in Scotland 1982-2002. Aliment Pharmacol Ther 2006; 24: 65-79.

6. Paimela $H$, Paimela L, Myllykangas-Luosujarvi R, Kivilaakso E. Current features of peptic ulcer disease in Finland: incidenceof surgery, hospital admissions and mortality for the disease during the past twenty-five years. Scand $\mathrm{J}$ Gastroenterol 2002; 37: 399-403.

7. Lanas A, García-Rodríguez LA, Polo-Tomás M, Ponce M, Alonso-Abreu I, Perez-Aisa MA, Perez-Gisbert J, Bujanda L, Castro M, Muñoz M, Rodrigo L, alvet X, Del-Pino D, Garcia S. Time trends and impact of upper and lower gastrointestinal bleeding and perforation in clinical practice. Am J Gastroenterol. 2009 Jul;104(7):1633-41.

8. Zhao, Y., and Encinosa, W. Hospitalizations for Gastrointestinal Bleeding in 1998 and 2006. HCUP Statistical Brief \#65. December, 2008. Agency for Healthcare Research and Quality, Rockville, MD. http://www.hcupus.ahrq.gov/reports/statbriefs/sb65.pdf

9. Bardhan KD, Royston C. Time, change and peptic ulcer disease in Rotherham, UK. Dig Liver Dis. 2008 Jul;40(7):540-6.

10. Paimela $H$, Oksala NK, Kivilaakso E. Surgery for peptic ulcer today. A study on the incidence, methods and mortality in surgery for peptic ulcer in Finland between 1987 and 1999. Dig Surg. 2004;21(3):185-91.

11. Lanas A, Perez-Aisa MA, Feu F, Ponce J, Saperas E, Santolaria S, Rodrigo L, Balanzo J, Bajador E, Almela P, Navarro JM, Carballo F, Castro M, Quintero E; Investigators of the Asociación Española de Gastroenterología (AEG). A nationwide study of mortality associated with hospital admission due to severe gastrointestinal events and those associated with nonsteroidal antiinflammatory drug use. Am J Gastroenterol. 2005 Aug;100(8):1685-93. 
12. Steven Harris. Medicare Severity-Refined DRGs: An Improved System. www.irp.com.

13. Raiford DS, Pérez Gutthann S, García Rodríguez LA. Positive Predictive value of ICD-9 codes in the identification of cases of complicated peptic ulcer disease in the Saskatchewan hospital automated database. Epidemiology 1996; 7:101104.

14. Sadic J, Borgström A, Manjer J, Toth E, Lindell G. Bleeding peptic ulcer - time trends in incidence, treatment and mortality in Sweden. Aliment Pharmacol Ther. 2009 Aug 15;30(4):392-8.

15. Hermansson M, Ekedahl A, Ranstam J, Zilling T. Decreasing incidence of peptic ulcer complications after the introduction of the proton pump inhibitors, a study of the Swedish population from 1974-2002. BMC Gastroenterol. 2009 Apr 20;9:25.

16. Bak Andersen I, Bonnevie O, Jorgensen T, Sorensen T. Time Trends for peptic ulcer disease in Danmark, 1981-1993. Analysis of hospitalization register and mortalitydata. Scand J Gastroenterol 1998; 33: 260-6.

17. Pérez-Aisa MA, Del Pino D, Siles M, Lanas A. Clinical trends in ulcer diagnosis in a population with high prevalence of Helicobacter pylori infection. Aliment Pharmacol Ther. 2005 Jan 1;21(1):65-72.

18. Lanas A, Esplugues JV, Zapardiel J, Sobreviela E. Education-based approach to addressing non-evidence-based practice in preventing NSAID-associated gastrointestinal complications. World J Gastroenterol. 2009 Dec 21;15(47):5953-9.

19. Sturkenboom MC, Burke TA, Dieleman JP, Tangelder MJ, Lee F, Goldstein JL. Underutilization of preventive strategies in patients receiving NSAIDs. Rheumatology (Oxford). 2003 Nov;42 Suppl 3:iii23-31.

20. Barkun AN, Martel M, Toubouti Y, Rahme E, Bardou M. Endoscopic hemostasis in peptic ulcer bleeding for patients with high-risk lesions: a series of metaanalyses. Gastrointest Endosc. 2009 Apr;69(4):786-99.

21. Bardhan KD, Williamson M, Royston C, Lyon C. Admission rates for peptic ulcer in the trent region, UK, 1972--2000. changing pattern, a changing disease? Dig Liver Dis. 2004 Sep;36(9):577-88.

22. Lanas A, García-Rodríguez LA, Arroyo MT, Gomollón F, Feu F, GonzálezPérez A, Zapata E, Bástida G, Rodrigo L, Santolaria S, Güell M, de Argila CM, Quintero E, Borda F, Piqué JM; Asociación Española de Gastroenterología. Risk of upper gastrointestinal ulcer bleeding associated with selective cyclooxygenase-2 inhibitors, traditional non-aspirin non-steroidal anti-inflammatory 
drugs, aspirin and combinations. Gut. 2006 Dec;55(12):1731-8. Epub 2006 May 10.

23. Humes DJ, Solaymani-Dodaran M, Fleming KM, Simpson J, Spiller RC, West J. A population-based study of perforated diverticular disease incidence and associated mortality. Gastroenterology. 2009 Apr;136(4):1198-205. 
Table 1: Accuracy of codes for the final diagnosis after validation of clinical history for five major causes of specific gastrointestinal complication events.

\begin{tabular}{|c|c|c|c|}
\hline $\begin{array}{l}\text { Recorded } \\
\text { discharge } \\
\text { diagnosis code } \\
\text { before validation }\end{array}$ & $\begin{array}{l}\text { Number of } \\
\text { patients }\end{array}$ & $\begin{array}{c}\text { Cases validated } \\
\mathrm{n}(\%)\end{array}$ & $\begin{array}{l}\text { Actual diagnosis after } \\
\text { validation } \\
\mathrm{n}(\%)\end{array}$ \\
\hline $\begin{array}{l}\text { Peptic ulcer } \\
\text { Bleeding }\end{array}$ & 13616 & $1241(9.1 \%)$ & $\begin{array}{c}1218(98.1 \%)=\text { peptic ulcer } \\
\text { bleeding } \\
23(1.8 \%)=\text { Other }\end{array}$ \\
\hline $\begin{array}{l}\text { Peptic Ulcer } \\
\text { Perforation }\end{array}$ & 1655 & $138(8.3 \%)$ & $\begin{array}{c}129(93.5 \%)=\text { peptic ulcer } \\
\text { perforation } \\
9(6.5 \%)=\text { Other }\end{array}$ \\
\hline $\begin{array}{l}\text { Diverticulosis or } \\
\text { Diverticulitis with } \\
\text { bleeding }\end{array}$ & 2130 & $193(9.1 \%)$ & $\begin{array}{c}189(97.9 \%)=\text { colonic } \\
\text { diverticular bleeding } \\
4(2 \%)=\text { Other }\end{array}$ \\
\hline $\begin{array}{l}\text { Angiodysplasia } \\
\text { Bleeding }\end{array}$ & 597 & $69(11.6 \%)$ & $\begin{array}{c}66(95.7 \%)=\text { intestinal (lower } \\
\text { Gl) angiodysplasia } \\
3(4.3 \%)=\text { Other }\end{array}$ \\
\hline $\begin{array}{l}\text { Intestinal } \\
\text { perforation }\end{array}$ & 759 & $441(58.1 \%)$ & $\begin{array}{c}422(95.7 \%)=\text { intestinal } \\
\text { perforation } \\
26(5.9 \%)=\text { Other }\end{array}$ \\
\hline Total (5 causes) & 18757 & $2082(11.1 \%)$ & $\begin{array}{c}2024(97.2 \%)=\text { Accurate } \\
58(2.85)=\text { Other }\end{array}$ \\
\hline
\end{tabular}


Table 2: Age and gender distribution by lesion type.

a)

\begin{tabular}{|l|c|c|c|}
\hline & $\mathrm{n}$ & $\begin{array}{c}\text { Age } \\
(\text { Mean, SD) }\end{array}$ & $\begin{array}{c}\text { Male Gender } \\
(\mathrm{n}, \%)\end{array}$ \\
\hline Peptic ulcer bleeding & 13616 & $63.50(16.7)$ & $9615(70.6 \%)$ \\
\hline Peptic ulcer perforation & 1655 & $55.13(19.1)$ & $1050(69.5 \%)$ \\
\hline $\begin{array}{l}\text { Diverticulosis or } \\
\text { Diverticulitis with bleeding }\end{array}$ & 2130 & $75.91(10.2)$ & $950(44.6 \%)$ \\
\hline Angiodysplasia Bleeding & 597 & $73.32(11.6)$ & $333(55.9 \%)$ \\
\hline Intestinal perforation & 759 & $63.37(18.6)$ & $414(54.5 \%)$ \\
\hline
\end{tabular}

Mean comparison among categories: $p$-value $<0.001$ 


\section{Figure Legends}

Figure 1: Estimated number of peptic ulcer, colonic diverticular, and angiodysplasia bleeding events per 100,000 person-years based on the adjudication of events in the validation process. Regression coefficients of temporal trends were: $R^{2}=0.944(p<0.0001)$ for peptic ulcer bleeding rates; $R^{2}$ $=0.443(p=0.03)$ for colonic diverticular bleeding rates; $R^{2}=0.715(p=0.002)$ for angiodysplasia bleeding rates.

Figure 2: Estimated number of perforations per 100,000 person-years based on the adjudication of events in the validation process. Regression coefficients of temporal trends were: $R^{2}=0.410(p=0.04)$ for peptic ulcer perforation; $R^{2}=$ $0.091(p=0.395)$ for intestinal perforation rates. 
Figure 1:

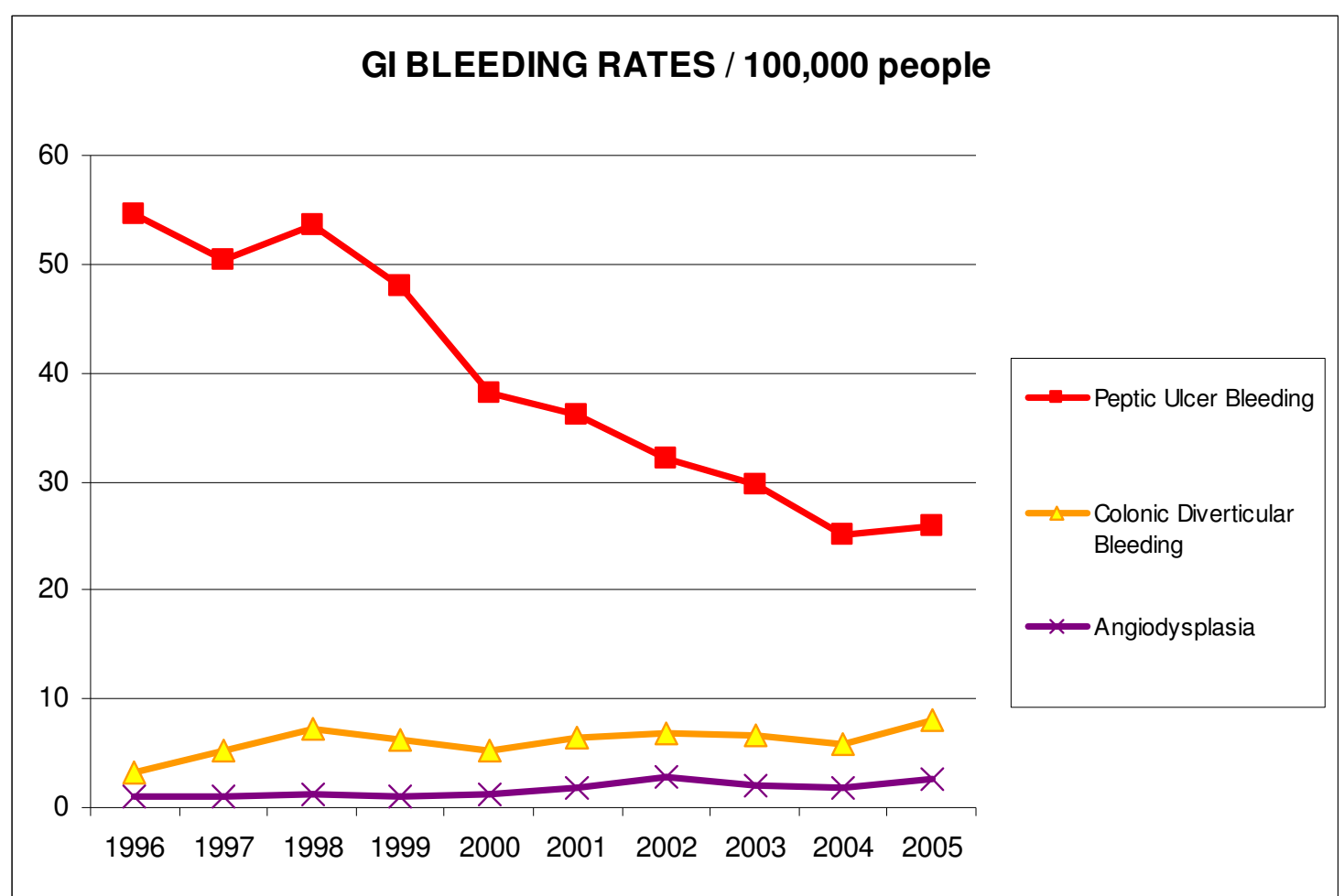


Figure 2:

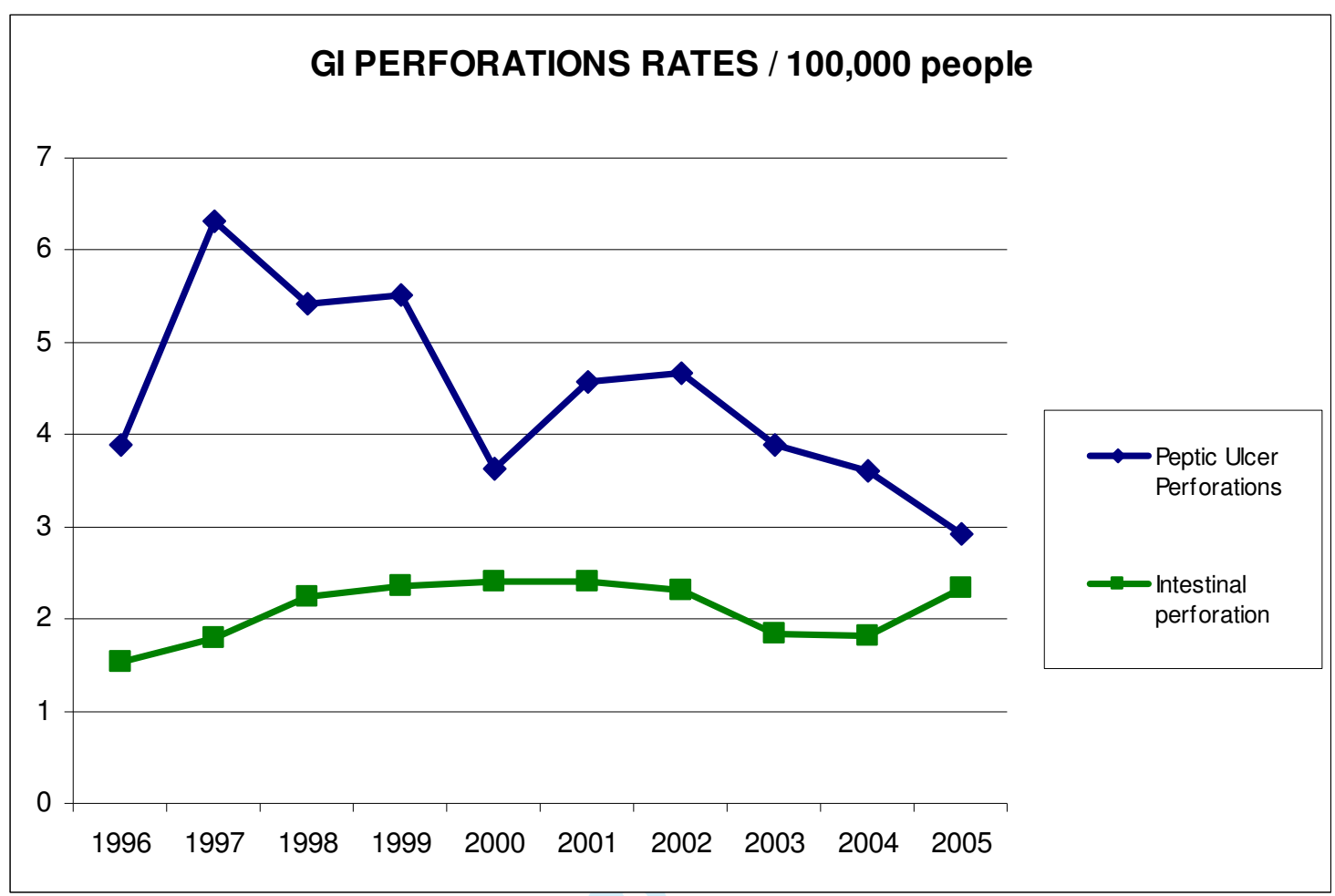




\section{Statements of interest:}

Acknowledgements: The study was supported by Pfizer Inc. Pfizer had no role in the conduct of the study, or the analysis or interpretation of the data.

\section{Information concerning the role of authors in the study}

Dr. Lanas and Dr Garcia Rodriguez designed the study. Dr. Lanas drafted the manuscript with major contributions from Mónica Polo-Tomás and Dr Luis Garcia Rodriguez. All the authors contributed to the collection of data and had full access to the raw data set from the study, the results, the manuscript, and made their own comments and contributions. Dr. Dolores Del-Pino designed the data extraction process for the ICD-9 codes. Mónica Polo-Tomás introduced the data in the database and, with Luis Alberto Garcia Rodriguez and Dr Lanas, checked the quality of the data base. Mónica Polo-Tomás produced the outputs and ran the statistical analysis with Dr. Garcia Rodriguez. Dr. Lanas acted as guarantor of the submission.

\section{Conflict of interest:}

Angel Lanas is member of the adjudication Committee of the international multicenter CONDOR trial, sponsored by Pfizer, and has received honoraria for lecturing at Pfizer- and AstraZeneca-sponsored symposiums.

Xavier Calvet has received honoraria for participating in advisory boards and for lecturing at AstraZeneca-sponsored symposiums. Javier P. Gisbert has received honoraria for lecturing at AstraZeneca- and Pfizer-sponsored symposiums. Luis Bujanda has received small honoraria for lecturing at Pfizersponsored symposiums.

The other study authors have no conflicts of interest to report. 
Supporting Information Table 1: Time trends of case fatality by lesion type $(n=18757)$. No statistical differences were found for any of the 5 types of lesions over time.

\begin{tabular}{|c|c|c|c|c|c|c|c|c|c|c|c|c|}
\hline \multirow{2}{*}{\multicolumn{2}{|c|}{ Mortality }} & \multicolumn{10}{|c|}{ Year } & \multirow{2}{*}{ Total } \\
\hline & & 1996 & 1997 & 1998 & 1999 & 2000 & 2001 & 2002 & 2003 & 2004 & 2005 & \\
\hline \multirow{2}{*}{$\begin{array}{l}\text { Peptic Ulcer } \\
\text { Bleeding }\end{array}$} & $\mathrm{n}$ & 46 & 59 & 57 & 53 & 41 & 29 & 45 & 40 & 39 & 18 & $427 / 13616$ \\
\hline & $\%$ & 2.5 & 3.5 & 3.2 & 3.2 & 3.1 & 2.2 & 4.0 & 3.7 & 4.2 & 1.9 & 3.1 \\
\hline \multirow{2}{*}{$\begin{array}{l}\text { Peptic ulcer } \\
\text { perforation }\end{array}$} & $\mathbf{n}$ & 19 & 19 & 16 & 21 & 21 & 16 & 17 & 15 & 10 & 10 & $164 / 1655$ \\
\hline & $\%$ & 9.5 & 8.2 & 8.9 & 11.4 & 13.5 & 10.0 & 10.3 & 10.6 & 7.6 & 9.2 & 9.9 \\
\hline \multirow{2}{*}{$\begin{array}{l}\text { Diverticular } \\
\text { Bleeding }\end{array}$} & $n$ & 0 & 3 & 6 & 5 & 5 & 6 & 5 & 4 & 5 & 4 & $43 / 2130$ \\
\hline & $\%$ & .0 & 1.8 & 2.5 & 2.5 & 2.8 & 2.7 & 2.1 & 1.6 & 2.3 & 1.3 & 2.0 \\
\hline \multirow{2}{*}{$\begin{array}{l}\text { Angiodysplasia } \\
\text { Bleeding }\end{array}$} & $\mathrm{n}$ & 2 & 2 & 1 & 4 & 2 & 3 & 9 & 1 & 2 & 4 & $30 / 597$ \\
\hline & $\%$ & 6.7 & 5.7 & 2.4 & 11.1 & 4.5 & 4.6 & 9.1 & 1.3 & 2.8 & 4.0 & 5.0 \\
\hline \multirow{2}{*}{$\begin{array}{l}\text { Intestinal } \\
\text { perforation }\end{array}$} & $n$ & 11 & 22 & 29 & 24 & 28 & 24 & 22 & 20 & 22 & 30 & $232 / 759$ \\
\hline & $\%$ & 21.2 & 36.1 & 36.3 & 30.8 & 30.1 & 28.2 & 25.9 & 30.3 & 31.0 & 34.1 & 30.6 \\
\hline
\end{tabular}


Supporting Information Table 2. Severity of events using several measures, by type of lesion based on the chart validation.

\begin{tabular}{|c|c|c|c|c|c|c|c|c|c|}
\hline Lesion & $\mathbf{N}$ & & Mortality & $\begin{array}{l}\text { Hospital } \\
\text { Stay } \\
\text { (days) }\end{array}$ & $\begin{array}{l}\text { Number of } \\
\text { diagnostic } \\
\text { tests } \\
\text { performed }\end{array}$ & $\begin{array}{c}\text { DRG } \\
\text { Weight }\end{array}$ & $\begin{array}{c}\text { Number of } \\
\text { Comorbidities }\end{array}$ & $\begin{array}{c}\text { Lowest } \\
\text { Hemoglobin } \\
\text { level }\end{array}$ & $\begin{array}{l}\text { Blood units } \\
\text { transfused }\end{array}$ \\
\hline \multirow{2}{*}{ Peptic Ulcer Bleeding } & \multirow{2}{*}{1218} & Mean (\%) & 1.69 & 6.93 & 1.04 & 1.13 & 1.55 & 9.18 & 1.51 \\
\hline & & $95 \% \mathrm{Cl}$ & {$[0.96,2.43]$} & {$[6.54,7,32]$} & {$[1,03,1,06]$} & {$[1.09,1.18]$} & {$[1.50,1.60]$} & {$[9.05,9.30]$} & {$[1.40,1.63]$} \\
\hline \multirow{2}{*}{ Peptic Ulcer Perforation } & \multirow{2}{*}{129} & Mean (\%) & 4.40 & 11.56 & 1.20 & 3.06 & 1.40 & 12.25 & 1.16 \\
\hline & & $95 \% \mathrm{Cl}$ & {$[0.10,8.69]$} & {$[8.74,14.38]$} & {$[1.04,1.36]$} & {$[2.52,3.61]$} & {$[1.23,1.56]$} & {$[11.65,12.85]$} & {$[0.25,2.08]$} \\
\hline \multirow{2}{*}{ Diverticular Bleeding } & \multirow{2}{*}{189} & Mean (\%) & 2.84 & 9.34 & 1.31 & \begin{tabular}{|l|}
1.28 \\
\end{tabular} & 2.07 & 10.14 & 1.28 \\
\hline & & $95 \% \mathrm{Cl}$ & {$[0.36,5.32]$} & {$[8.32,10.36]$} & {$[1.20,1.41]$} & {$[1.15,1.41]$} & {$[1.92,2.22]$} & {$[9.76,10.53]$} & {$[0.95,1.61]$} \\
\hline \multirow{2}{*}{ Angiodysplasia } & \multirow{2}{*}{6} & Mean (\%) & 1.56 & 8.84 & 1.34 & \begin{tabular}{|l|}
1.17 \\
\end{tabular} & 2.70 & 8.31 & 2.02 \\
\hline & & $95 \% \mathrm{Cl}$ & {$[0,4.68]$} & {$[6.58,11.10]$} & {$[1.04,1.64]$} & {$[1.06,1.29]$} & {$[2.41,3.00]$} & {$[7.78,8.85]$} & {$[1.54,2.50]$} \\
\hline \multirow[b]{2}{*}{ Intestinal perforation } & \multirow[b]{2}{*}{422} & Mean (\%) & 28.66 & 21.78 & 0.99 & 4.04 & 1.85 & 10.96 & 0.91 \\
\hline & & $95 \% \mathrm{Cl}$ & $\begin{array}{l}{[23.58} \\
33.75]\end{array}$ & $\begin{array}{l}{[19.21} \\
24.35]\end{array}$ & {$[0.92,1.05]$} & {$[3.64,4.43]$} & {$[1.73,1.97]$} & {$[10.66,11.27]$} & {$[0.59,1.24]$} \\
\hline
\end{tabular}

Comparisons among categories:

- Mortality:

$\circ \quad$ Intestinal perforation vs. Any other lesion: $p<0.001$

- Peptic Ulcer Bleeding vs. Peptic Ulcer Perforation: $p=0.363$ (NS)

- Hospital stay: Peptic Ulcer Bleeding vs. Peptic Ulcer Perforation: $p<0.001$

- Number of diagnostic tests performed:

- Angiodysplasia vs. Peptic Ulcer Bleeding: $p<0.001$

- Angiodysplasia vs. Peptic Ulcer Perforation: $p=0.019$ (NS)

$\circ$ Angiodysplasia vs. Diverticular Bleeding: $p=0.905$ (NS)

$\circ$ Angiodysplasia vs. Intestinal perforation: $p<0.001$

$\bigcirc$ Diverticular Bleeding vs. Peptic Ulcer Bleeding: $p<0.001$

$\circ$ Diverticular Bleeding vs. Peptic Ulcer Perforation: $p=0.012$ (NS)

○ Diverticular Bleeding vs. Intestinal perforation: $p<0.001$

- Number of Comorbidities: 
- Angiodysplasia vs. Any other lesion: $p<0.001$

$\circ$ Diverticular Bleeding vs. Any other lesion: $p<0.001$

- Lowest Hemoglobin level:

○ Angiodysplasia vs. Peptic Ulcer Bleeding: $p=0.012$ (NS)

$\circ$ Angiodysplasia vs. Peptic Ulcer Perforation: $p<0.001$

- Angiodysplasia vs. Diverticular Bleeding: $p<0.001$

- Angiodysplasia vs. Intestinal perforation: $p<0.001$

- Peptic Ulcer Bleeding vs. Peptic Ulcer Perforation: $p<0.001$

- Blood units transfused:

- Angiodysplasia vs. Peptic Ulcer Bleeding: $p=0.226$ (NS)

$\circ$ Angiodysplasia vs. Peptic Ulcer Perforation: $p=0.035$

0 Angiodysplasia vs. Diverticular Bleeding: $p=0.087$ (NS)

0 Angiodysplasia vs. Intestinal perforation: $p=0.002$

$\circ$ Peptic Ulcer Bleeding vs. Peptic Ulcer Perforation: $p=0.252$ (NS) 
Supporting Information Table 3: NSAID, Low-Dose Aspirin, PPI use recorded in the charts by lesion type

\begin{tabular}{|c|c|c|c|c|c|c|c|}
\hline \multirow{2}{*}{\multicolumn{2}{|c|}{ Recorded Drug Use }} & \multicolumn{5}{|c|}{ Cause } & \multirow{2}{*}{$\begin{array}{c}\text { Total } \\
(\mathrm{N}=2024)\end{array}$} \\
\hline & & $\begin{array}{l}\text { Peptic Ulcer } \\
\text { Bleeding } \\
(\mathrm{N}=1218)\end{array}$ & $\begin{array}{l}\text { Peptic } \\
\text { Ulcer } \\
\text { Perforation } \\
\quad(\mathrm{N}=129)\end{array}$ & $\begin{array}{l}\text { Diverticular } \\
\text { Bleeding } \\
(\mathrm{N}=189)\end{array}$ & $\begin{array}{l}\text { Angiodysplasia } \\
\qquad(\mathrm{N}=66)\end{array}$ & $\begin{array}{l}\text { Intestinal } \\
\text { perforation } \\
(\mathrm{N}=422)\end{array}$ & \\
\hline \multirow{2}{*}{ Any NSAID or Low- ASA } & $\mathbf{n}$ & 533 & 22 & 65 & 15 & 40 & 675 \\
\hline & $\%$ & $44.2 \%$ & $17.1 \%$ & $34.4 \%$ & $22.7 \%$ & $9.5 \%$ & $33.5 \%$ \\
\hline \multirow{2}{*}{ NSAID } & $\mathbf{n}$ & 371 & 20 & 28 & 11 & 12 & 442 \\
\hline & $\%$ & $30.7 \%$ & $15.5 \%$ & $14.8 \%$ & $16.7 \%$ & $2.8 \%$ & $22.0 \%$ \\
\hline \multirow{2}{*}{ LOW DOSE ASA } & $\mathbf{n}$ & 191 & 3 & 41 & 4 & 28 & 267 \\
\hline & $\%$ & $15.8 \%$ & $2.3 \%$ & $21.7 \%$ & $6.1 \%$ & $6.6 \%$ & $13.3 \%$ \\
\hline \multirow{2}{*}{ PPI } & $\mathbf{n}$ & 92 & 7 & 48 & 19 & 30 & 196 \\
\hline & $\%$ & $7.6 \%$ & $5.4 \%$ & $25.4 \%$ & $28.8 \%$ & $7.1 \%$ & $9.7 \%$ \\
\hline \multirow{2}{*}{ NSAID + PPI } & $\mathbf{n}$ & 27 & 1 & 7 & 5 & 2 & 42 \\
\hline & $\%$ & $2.2 \%$ & $0.8 \%$ & $3.7 \%$ & $7.6 \%$ & $0.5 \%$ & $2.1 \%$ \\
\hline \multirow{2}{*}{ Low-Dose ASA + PPI } & $\mathbf{n}$ & 20 & 0 & 14 & 2 & 11 & 47 \\
\hline & $\%$ & $1.7 \%$ & $0.0 \%$ & $7.4 \%$ & $3.0 \%$ & $2.6 \%$ & $2.3 \%$ \\
\hline \multirow{2}{*}{ Anticoagulant } & $\mathbf{n}$ & 69 & 1 & 27 & 18 & 15 & 130 \\
\hline & $\%$ & $5.7 \%$ & $0.8 \%$ & $14.3 \%$ & $27.3 \%$ & $3.6 \%$ & $6.5 \%$ \\
\hline
\end{tabular}

* $p$-value $<0.001$ among categories

- $\quad$ Any NSAID or Low- ASA:

O Peptic Ulcer Bleeding vs. Peptic Ulcer Perforation: $p<0.001$

$\circ$ Peptic Ulcer Bleeding vs. Diverticular Bleeding: $p=0.022$ (NS)

$\circ$ Peptic Ulcer Bleeding vs. Angiodysplasia: $p=0.001$ 
○ Peptic Ulcer Bleeding vs. Intestinal perforation: $p<0.001$

- NSAID:

○ Peptic Ulcer Bleeding vs. Peptic Ulcer Perforation: $p<0.001$

- Peptic Ulcer Bleeding vs. Diverticular Bleeding: $p<0.001$

- Peptic Ulcer Bleeding vs. Angiodysplasia: $p=0.021$ (NS)

0 Peptic Ulcer Bleeding vs. Intestinal perforation: $p<0.001$

- Low- ASA:

○ Diverticular Bleeding vs. Peptic Ulcer Bleeding: $p=0.080$ (NS)

0 Diverticular Bleeding vs. Peptic Ulcer Perforation: $p<0.001$

- Diverticular Bleeding vs. Angiodysplasia: $p=0.004$

○ Diverticular Bleeding vs. Intestinal perforation: $p<0.001$

- PPI:

○ Diverticular Bleeding vs. Peptic Ulcer Bleeding: $p<0.001$

○ Diverticular Bleeding vs. Peptic Ulcer Perforation: $p<0.001$

0 Diverticular Bleeding vs. Angiodysplasia: $p=0.813$ (NS)

$\circ$ Diverticular Bleeding vs. Intestinal perforation: $p<0.001$

- NSAID + PPI:

$\bigcirc$ Angiodysplasia vs. Peptic Ulcer Bleeding: $p=0.008$

$\circ$ Angiodysplasia vs. Peptic Ulcer Perforation: $p=0.005$

- Angiodysplasia vs. Diverticular Bleeding: $p=0.128$ (NS)

$\circ$ Angiodysplasia vs. Intestinal perforation: $p=0.001$

- Low- ASA + PPI:

○ Diverticular Bleeding vs. Peptic Ulcer Bleeding: $p<0.001$

0 Diverticular Bleeding vs. Peptic Ulcer Perforation: $p<0.001$

$\circ \quad$ Diverticular Bleeding vs. Angiodysplasia: $p=0.127$ (NS)

$O$ Diverticular Bleeding vs. Intestinal perforation: $p=0.001$

- Anticoagulants 
Peptic Ulcer Bleeding vs. Peptic Ulcer Perforation: $p=0.103$ (NS)

- Peptic Ulcer Bleeding vs. Diverticular Bleeding: $p<0.001$

Peptic Ulcer Bleeding vs. Angiodysplasia: $p<0.001$

○ Peptic Ulcer Bleeding vs. Intestinal perforation: $p=0.376$ (NS) 


\section{Reply to comments from the Editor and Referees}

\section{EDITOR'S COMMENTS TO AUTHOR:}

a) Please can you work on the standard of English - it is sub-optimal.

Reply: The manuscript was submitted to a professional English medical editing service for correction and revision of the English language (www.sanfranciscoedit.com).

b) Please would you make Table 3 to be Supporting Information Table 1, and label the two duplicate Tables 4 \& 5 as Supporting Information Tables 2 and 3. [Supporting Information is available to readers on-line. The important / significant results should be mentioned in the text, and the supporting information referred to in the text. This is explained in the Author Guidelines at www.APandT.org or at http://authorservices.wiley.com/bauthor/suppmat.asp ].

Reply: We made this change and incorporated the main data from Tables 3, 4, and 5 into the text. These Tables have been converted to Supporting Information Tables 1, 2 and 3.

c) Can you really look at your paper, and make it clear what's new - in addition to your already well-cited earlier paper?

Reply: We reworked the introduction and discussion to clarify what it is new in this manuscript. Below is the list of the new information provided:

a) time trends for hospitalizations due to peptic (gastric and duodenal) ulcer bleeding and its contrast with peptic ulcer perforation

b) time trends for intestinal perforation

c) time trends for colonic diverticular bleeding

d) time trends for bleeding due to angiodysplasia

e) mortality rates of these events

f) description of severity characteristics of these lesions

g) recorded drug use for each of these entities. We outlined the association between anticoagulant use with both diverticular bleeding and angiodysplasia, which we believe is of utmost importance.

\section{Reviewer: 1}

We thank referee 1 for saying that we adequately addressed the prior comments. Concerning the new comments:

a) Abstract

The aim does not make sense: "To report temporal changes in the incidence of five major cause-specific gastrointestinal (GI) bleeding and perforation." Do the authors mean the incidence of five major cause-specific gastrointestinal (GI) events?

Reply: We revised the sentence accordingly.

Introduction 
1. The first sentence is vague, and could mean anything: "Gastrointestinal complications are major causes of GI hospitalization." In any case, they need to make it clear that GI is an abbreviation of gastrointestinal in this sentence.

Reply: We revised the sentence accordingly, and defined the abbreviation. We believe the sentence specifies a clear and important fact, which is essential to our paper.

2. The statement on two occasions in the Introduction that "...no cause specific analyses were performed" as part of their previous study (reference 7), and that "...trends for the specific cause of lower GI complications were not reported" as part of their previous study again leaves me with the feeling that this is a post hoc analysis of data in an attempt to obtain another publication from the same piece of work. Why weren't these analyses performed in the prior publication if, as the authors presumably believe, this is important information?

Reply: We now make clear that this piece of information was not reported. As we responded to the editor, the data presented are new and it well know that databases with extensive data can provide important information that cannot always be included in a single publication.

Methods

1. Page 6, line 42/43. I think the authors mean that "...gastroenterologists or trained GI residents with experience of these types of studies." rather than "...on this type of studies."

2. Page 6, line 56/57. There is now no mention whatsoever of what DRG is an abbreviation of. This needs to be added.

Reply: We changed the text in accordance with these suggestions.

Results

1. Page 8, lines 7 to 10 don't make sense: “...information provided by the participant hospitals showed and statistically significant decrease..." The authors mean "... a statistically significant..."

2. Page 9, lines 19/20: “...length of hospitalization were higher...” should be “...was higher...”

3. Page 9, lines 24/25: “...from the lower GI tract when compared those...” should be "...when compared with those..."

Reply: The text was corrected by a professional editing service to improve the readability of the manuscript.

Discussion

The authors state on page 11 , lines 8 to 11 that: "Time trends on peptic ulcer perforation are rarely reported and those available show no change or small changes overtime." They reference their previous study here. This makes it seem as though the results of the current study are at odds with those of the previous study, yet how can this be the case, as they are derived from the same dataset?!

Reply: The referee is right. We included this reference because it reported overall trends, but clearly it should not be there. We have removed reference 7 .

Reviewer: 2

Comments for Transmission to the Authors

None 
Reply: We thank reviewer 2 for being comfortable with our previous reply. 